\section{Emotional distress in Angolan patients with several types of tuberculosis}

Paulo Benvinda Xavier ${ }^{1}$, Bruno Peixoto ${ }^{2}$

1. Sanatorium Hospital of Huambo. Huambo/ Angola.

2. CESPU, Instituto Superior de Ciências da Saúde- Norte (SciencesDepartment). Gandra/ Portugal.

\section{Abstract}

Background: There is growing evidence that emotional distress expressed in terms of anxiety and depression is very high among tuberculosis (TB) patients.

Objectives: This study aims to determine levels of anxiety, depression and emotional distress in patients with several types of $\mathrm{TB}$ and to determine the association between social-demographic and economical factors, clinical variables and anxiety, depression and emotional distress.

Methods: A cross-sectional study was performed in a sample of 81 TB patients. A social-demographic and economical questionnaire was used, followed by the hospital anxiety and depression scale. Results: $38.3 \%$ and $49.4 \%$ of our sample presented significant levels of anxiety and depression. $44.4 \%$ of patients had sigrelated to higher risk for anxiety. Gender, extra-pulmonary and multidrug resistant TB were associated to depression. Female related to higher risk for anxiety. Gender, extra-pulmonary and multidrug resistant TB were
gender and cases of extra-pulmonary TB presented a 1.5 times risk for emotional distress.

Conclusions: Our study found high rates of anxiety, depression and emotional distress among TB patients. Marital status, Conclusions: Our study found high rates of anxiety, depression and emotional distress among TB patients. Marital status,
gender, type and treatment of TB were related to higher levels of emotional disorder. Mental health services should be an integral part of programs against tuberculosis.

Keywords: Anxiety, Depression, Common Mental Disorders, Mycobacterium tuberculosis, Miliary Tuberculosis, Pulmonar Tuberculosis, Pott's Disease, Huambo.

\section{DOI: http://dx.doi.org/10.4314/ahs.v15i2.10}

\section{Introduction} Tuberculosis (TB) is an ancient disease with elevated the national coordinator of the program against tuberrates of incidence and prevalence mostly in low and culosis, this numbers will continue to rise in the next middle-income countries. In 2013, 60,807 cases of all years ${ }^{3}$.

forms of TB were notified in Angola. Prevalence and

incidence are estimated in 423 and 320 respectively, per The recognition that common mental disorders (CMD) 100,000 inhabitants ${ }^{1}$. At the same year 6900 deaths were need to be placed alongside other pathologies associated TB related and 1600 were result of TB and HIV co-in- with low income and poverty ${ }^{4}$ and that these disorders fection ${ }^{1}$. Huambo province it is located at the center of are a significant source of disability across cultures ${ }^{5}$, is Angola. It has a population of over 1.5 million persons. not new. However the association between CMD and TB is recent. It is now clear that anxiety, depression and emotional distress are significant dimensions on the burden and disability of the disease ${ }^{6}$ and that they are intimately related to the severity of symptoms, to the number of reported symptoms, to higher rates of health services use, to low treatment compliance, to a more extensive course of treatment, to a reduced control of the disease and to death ${ }^{6,7,8,9}$.

CESPU, Instituto Superior de

Ciências da Saúde-Norte

Rua Central de Gandra, 1317

4585-116 Gandra. Portugal

00351962501501

00351224157177

Email: bruno.peixoto@iscsn.cespu.pt
According to Peltzer and colleagues ${ }^{10}$, few studies have investigated the relation between $\mathrm{TB}$ and $\mathrm{CMD}$ in middle and low-income countries.Despite the reduced number of studies on the subject, there is growing evidence that emotional distress expressed in terms of anxiety and depression is very high. In an Ethiopian sample $46.7 \%$ of the TB patients with HIV negative status presented with significant levels of distress, this number raises to $63.7 \%$ in TB patients with HIV positive status ${ }^{11}$. A South African study concluded that $87 \%$ of the TB patients presented with significant emotional distress ${ }^{10}$. A recent study in Pakistan determined that $37.1 \%$ of TB patients from an outpatient clinic had anxiety and depression according to the Hospital Anxiety and Depression Scale (HADS) ${ }^{12}$. A Brazilian study found a $34 \%$ increase in the presence of pulmonary $\mathrm{TB}$ among individuals with CMD namely at the level of depressive mood and thoughts?

Therefore further epidemiological studies are needed to determine the severity of emotional distress in TB and to increase the understanding of the relationship between medical and social factors ${ }^{9,10}$

The present study aims to determine levels of anxiety, depression and emotional distress in patients with several types of TB from the Sanatorium Hospital of Huambo. We also aim to determine the association between social-demographic and economical factors, clinical variables and anxiety, depression and emotional distress.

\section{Methods}

A cross sectional study was performed from December 2013 to April 2014. The sample comprised 81 patients, from years, admitted in the Sanatorium Hospital of Huambo
with several types of TB. Patients with an altered state of consciousness and with comprehension difficultie during the initial questionnaire were excluded. Table 1 shows the characteristics of the sample. The majority were male $(58 \%)$, with ages between 25 to 34 years $(34.6 \%)$, single $(50.6 \%)$, with school attendance at the elementary level $(54.3 \%)$.

According to socioeconomic status, the majority of the subject had a house $(61.7 \%)$ and daily access to food $(61.7 \%)$ but they did not have access to electricity $(86.4 \%)$ or potable water $(54.3 \%)$ and most of them did not have a monthly income $(50.6 \%)$. Those who have a wage, received less than 5000 Kwanzas per month $(57.5 \%)$. The majority of patients admitted for the firs time $(79 \%)$, were HIV negative $(96.3 \%)$ and had a diagnosis of pulmonary TB $(77.8 \%)$ non resistant to conventional TB treatment $(74.1 \%)$.

A social-demographic and economical questionnaire was used, followed by the Hospital Anxiety and Depression Scale (HADS) in order to determine the levels of depression, anxiety and emotional distress. HADS comprises two factors corresponding to anxiety and depression, which share a common variance with a primary factor - emotional distress ${ }^{13,14}$. It is defined that optimal balance between sensitivity and specificity is achieved when caseness is defined by a score of 8 or above on both Anxiety and Depression ${ }^{15}$ A cut-off 15 for emotional distress is acceptable ${ }^{16}$.

Clinical data was collected through the attending physician. Statistical analysis was performed via IBM SPSS Statistics 22. Initially, we obtained the frequencies and percentages for each variable, followed by Pearsnon's

Chi-Square and odds ration and risk estimate. The study was approved by the directive board of the Sanatorium Hospital of Huambo, and all participants gave their informed consent.

Results

Table 2 shows the frequencies according to different levels of anxiety. According to that table, $38.3 \%$ of our sample presented with significant clinical levels of anxiety, with severity ranging from mild to very high. 
Table 1. Social-demographic, economical and clinical characteristics of the sample

\begin{tabular}{|c|c|c|}
\hline & & \\
\hline Gender & $\mathbf{n}$ & $\%$ \\
\hline $\begin{array}{l}\text { Male } \\
\text { Female }\end{array}$ & 47 & 58 \\
\hline Age (in years) & & \\
\hline $15-24$ & 23 & 28.4 \\
\hline $\begin{array}{l}25-34 \\
35-44\end{array}$ & 28 & 34.6 \\
\hline $\begin{array}{l}35-44 \\
45-54\end{array}$ & 13 & \\
\hline $55-64$ & $\begin{array}{c}11 \\
6\end{array}$ & $\begin{array}{l}13.6 \\
7.4\end{array}$ \\
\hline Marital Status & & \\
\hline $\begin{array}{l}\text { Single } \\
\text { Married }\end{array}$ & $\begin{array}{l}41 \\
31\end{array}$ & $\begin{array}{l}50.6 \\
38.3\end{array}$ \\
\hline Divorced & 3 & \\
\hline Widow & 6 & 7.4 \\
\hline School Level & & \\
\hline Elementary school & 44 & 54.3 \\
\hline Preparatory school & 15 & 18.5 \\
\hline High school & 3 & 3.7 \\
\hline Do you have a house? & & \\
\hline $\begin{array}{l}\text { Yes } \\
\text { No }\end{array}$ & $\begin{array}{l}50 \\
31\end{array}$ & $\begin{array}{l}61.7 \\
38.3\end{array}$ \\
\hline Do you have daily access to fo & & \\
\hline Yes & 50 & 61.7 \\
\hline & 31 & 38.3 \\
\hline Do you have access to electrici & $\begin{array}{l}\text { ty? } \\
11\end{array}$ & \\
\hline & 70 & $\begin{array}{l}86.4 \\
86.4\end{array}$ \\
\hline Do you have access to potable & & \\
\hline water? & 19 & 23.5 \\
\hline & 44 & 54.3 \\
\hline Do you have a monthly wage? & & \\
\hline $\begin{array}{cc}\text { Yes } \\
\text { No }\end{array}$ & $\begin{array}{l}40 \\
41\end{array}$ & 50.6 \\
\hline Monthly Income (in Kwanzas & & \\
\hline $5000-10.000$ & 6 & 15 \\
\hline $5000-10.000$ & 9 & 22.5 \\
\hline $\begin{array}{l}5000-10.000 \\
\text { Number of admissions }\end{array}$ & & \\
\hline Number of admissions First & 64 & 79 \\
\hline More than once & 17 & 21 \\
\hline Negative & 78 & 96.3 \\
\hline Positive & 3 & 3.7 \\
\hline $\begin{array}{l}\text { TB Diagnosis } \\
\text { Pulmonary Tuberculosis }\end{array}$ & & \\
\hline $\begin{array}{l}\text { Pulmonary Tuberculosis } \\
\text { Miliary Tuberculosis }\end{array}$ & 63 & $\begin{array}{l}77.8 \\
14.8\end{array}$ \\
\hline $\begin{array}{l}\text { Millary 1uberculosis } \\
\text { Pott's Disease }\end{array}$ & 4 & 4.9 \\
\hline $\begin{array}{l}\text { Ganglionic Tuberculosis } \\
\text { TB treatment }\end{array}$ & 2 & 2.5 \\
\hline Regular & 60 & 74.1 \\
\hline Multidrug Restistant & 21 & 25.9 \\
\hline
\end{tabular}

Table 2. Levels of anxiety in the sample according to HADS

\begin{tabular}{lcc} 
& $\mathbf{n}$ & $\mathbf{\%}$ \\
\hline $\mathbf{( 0 - 7 )}$ None/low & 50 & 61.7 \\
$(\mathbf{8 - 1 0 )}$ Borderline abnormal & 14 & 17.3 \\
(11-21) Abnormal & 17 & 21 \\
\hline
\end{tabular}

In table 3 the frequency and percentage of different our sample presented with clinical significant levels of levels of depression in the sample are displayed accord- depression. Using a cut-off score of 15 for the total of ing to the HADS scores. We can infer that $49.4 \%$ of HADS, $44.4 \%(n=36)$ presented with significant levels of emotional distress.

\section{Table 3. Levels of depression in the sample according to HADS}

\begin{tabular}{lcc}
\cline { 2 - 3 } & $\mathbf{n}$ & $\mathbf{\%}$ \\
\hline (0 - 7) None/low & 41 & 50.6 \\
$(\mathbf{8}-10)$ Borderline abnormal & 20 & 24.7 \\
$(11-21)$ Abnormal & 20 & 24.7 \\
\hline
\end{tabular}

In table 4 and 5 we can observe the frequencies and other marital statuses, a diagnosis of extra-pulmonary percentages of each variable that showed sionificant TB and multidrug resistant TB were also related to differences according to two levels of anxiety and de- higher risk for clinical significant anxiety. Higher levpression (none or low and clinical significant) as well as els of depression were related to gender, with a 1.722 the odds ratio. Married subjects of our sample revealed times higher risk for females, and to extra-pulmonary a risk for anxiety almost two times (1.1963) higher than and multidrug resistant TB.

Table 4. Association of variables with anxiety levels in TB patients

\begin{tabular}{|c|c|c|c|c|c|}
\hline & $\begin{array}{c}(0-7) \\
\text { None/low }\end{array}$ & $\begin{array}{c}(8-21) \\
\text { Clinical } \\
\text { Significant }\end{array}$ & $x^{2}$ & OR & $\begin{array}{l}\text { 95\% Confidence } \\
\text { Interval }\end{array}$ \\
\hline \multicolumn{6}{|l|}{ Marital Status } \\
\hline Married (n/\%) & $12 / 38.7$ & $19 / 61.3$ & & 1.963 & {$[1.228-3.14]$} \\
\hline Others $(\mathrm{n} / \%)$ & $38 / 76$ & $12 / 24$ & 11.264 & 0.395 & {$[0.222-0.69]$} \\
\hline \multicolumn{6}{|l|}{ Diagnosis } \\
\hline Pulmonary (n/\%) & $41 / 65.1$ & $22 / 34.9$ & & 0.133 & [0.041-0.425] \\
\hline Extra-pulmonary (n/\%) & $6 / 33.3$ & $12 / 66.7$ & 16.679 & 1.714 & {$[1.236-2.377]$} \\
\hline \multicolumn{6}{|l|}{ TB treatment } \\
\hline Regular (n/\%) & $43 / 71.7$ & $17 / 28.3$ & & 0.496 & {$[0.269-0.915]$} \\
\hline $\begin{array}{r}\text { Multidrug Resistant } \\
(\mathrm{n} / \%)\end{array}$ & $6 / 28.5$ & $15 / 71.5$ & 5.121 & 1.473 & {$[1.012-2.142]$} \\
\hline
\end{tabular}




\begin{tabular}{|c|c|c|c|c|c|}
\hline & $\begin{array}{c}(0-7) \\
\text { None/low }\end{array}$ & $\begin{array}{c}\text { (8-21) Clinical } \\
\text { Significant }\end{array}$ & $x^{2}$ & OR & $\begin{array}{c}95 \% \\
\text { Confidence } \\
\text { Interval }\end{array}$ \\
\hline \multicolumn{6}{|l|}{ Gender } \\
\hline Male (n/\%) & $30 / 63.8$ & $17 / 42.5$ & & 0.467 & {$[0.263-0.826]$} \\
\hline Female (n/\%) & $11 / 26.8$ & $23 / 57.5$ & 7.82 & 1.722 & {$[1.148-2.582]$} \\
\hline \multicolumn{6}{|l|}{ Diagnosis } \\
\hline Pulmonary (n/\%) & $39 / 74.6$ & $24 / 22,2$ & & 0.133 & {$[0.041-0.425]$} \\
\hline Extra-pulmonary (n/\%) & $2 / 25.4$ & $16 / 77.8$ & 16.679 & 1.714 & {$[1.236-2.377]$} \\
\hline \multicolumn{6}{|l|}{ TB treatment } \\
\hline Regular (n/\%) & $35 / 58.3$ & $25 / 41.7$ & & 0.496 & {$[0.269-0.915]$} \\
\hline Multidrug Resistant (n/\%) & $6 / 28.6$ & $15 / 71.4$ & 5.121 & 1.473 & {$[1.012-2.142]$} \\
\hline
\end{tabular}

Table 6 contains the frequencies, percentages and the ferences according to emotional distress. Female gender odds ratio for the variables that showed significant dif- and cases of extra-pulmonary TB presented a 1.5 times higher risk for emotional distress.

Table 6. Association of variables with emotional distress levels in TB patients

\begin{tabular}{|c|c|c|c|c|c|c|}
\hline & & $\begin{array}{c}(0-14) \\
\text { None/low }\end{array}$ & $\begin{array}{c}(15-42) \\
\text { Clinical } \\
\text { Significant }\end{array}$ & $x^{2}$ & OR & $\begin{array}{l}\text { 95\% Confidence } \\
\text { Interval }\end{array}$ \\
\hline \multicolumn{7}{|l|}{ Gender } \\
\hline & Male $(\mathrm{n} / \%)$ & $\begin{array}{l}31 / 66 \\
14 / 412\end{array}$ & $16 / 34$ & & 0.56 & {$[0.332-0.946]$} \\
\hline \multicolumn{7}{|l|}{ Diagnosis } \\
\hline & Pulmonary (n/\%) & $43 / 68.3$ & $20 / 31.7$ & & 0.171 & {$[0.053-0.551]$} \\
\hline Ext & a-pulmonary $(n / \%)$ & $2 / 11.1$ & $16 / 88.8$ & 12.52 & 1.527 & [1.164-2.005] \\
\hline
\end{tabular}

\section{Discussion}

The present study aimed to determine levels of anxiety, depression and emotional distress in patients with several types of TB and to establish the associations between those psychological domains and social-demographic and economical factors and clinical variables. We found clinical significant levels of anxiety in 38.3\% of the sample. Clinical significant depression was found in $49.4 \%$ of the patients. Emotional distress was identified in $44.4 \%$ of the patients. These results are very similar to those presented in the sparse literature avail-
Regarding the factors that underlie the emotional status, we found that clinical significant levels of anxiety are related to marital status, in which married patients showed almost two times more chances for presenting with anxiety, and that higher levels of depression were connected to gender, with women presenting 1.7 times more risk for depression. Extra-pulmonary and multidrug resistant $\mathrm{TB}$ were also associated to both anxiety and depression. Emotional distress was associated to female gender and to extra-pulmonary TB. These two variables represent approximately 1.5 times more risk for the presence of significant emotional distress. Surprising was the absence of significant contribution of social-economic variables to the emotional dimensions. The relation between poverty, lower education and emotional functioning has been documented in several studies $^{10,19,20}$.

However we must emphasize that our sample comprised subjects with low social-economical status. The majority did not have access to potable water or electricity, school attendance was at the elementary level and mos of the patients did not have a monthly wage. Therefore the influence of these variables on the emotional statu could have been clouded by the narrow variety of social-economical characteristics. The same reasoning can be made concerning the HIV status; our sample only had three patients with a positive HIV status. Mean-

while, the influence of gender ${ }^{17}$, marital status ${ }^{10,18,19}$ and severity of the disease $\mathrm{e}^{21}$ on the emotional sphere is well documented in worldwide researches.

imitations

The present study holds some limitations such as, the reduced number of participants, the non inclusion of patients with abusive alcohol consumption and being a cross-sectional study we could not make a casualty link between variables. Therefore, a longitudinal study with a larger sample should be conducted in the future. Such a study should clarify the casualty relationships between variables, namely the implications of the emotional variables to the course of the disease. Emotional distress and TB are associated with greater individual vulnerability and increased public health costs, these matters should be deepened in a future longitudinal research ${ }^{4,9}$.

\section{Conclusion}

Our study found high rates of anxiety, depression and emotional distress among tuberculosis patients from the Sanatorium Hospital of Huambo. Marital status, gender, type and treatment of TB were related to higher levels of emotional disorder. Mental health services should be an integral part of programs against tuberculosis.

\section{References}

1. World Health Organization. Global tuberculosis report 2014. Geneva: WHO/HTM/TB/2014.08.

2. http://www.redeangola.info/tuberculose-no-huambo/

3.http://www.dnoticias.pt/actualidade / mundo/437961-tuberculose-em-angola-e-problema-prioritario-de-saude-publica

4. Patel, V., \&Kleinman, A. Poverty and common menThe association between the psychological domains and tal disorders in developing countries. Bulletin of the TB is extremely intricate. Some authors advocate for the World Health Organization 2003; 81(8), 609-615.

direct effects of stress on immune functioning ${ }^{22}$ while 5. Ormel, J., VonKorff, M., Ustun, T. B., Pini, S., Koothers point to the role of social stigma associated to rten, A., \&Oldehinkel, T. Common mental disorders the disease $\mathrm{e}^{23,24,25}$. The finding that gender and marital and disability across cultures: results from the WHO status as well as the type and treatment of TB influence Collaborative Study on Psychological Problems in Genemotional functioning seems to foster the idea of an eral Health Care. JAMA 1994; 272(22), 1741-1748. interaction between social and biolooical mechanisms. 6. Husain, M. O., Dearman, S. P., Chaudhry, I. B., RizAlthough the study of the relation between psychologi- vi, N., \&Waheed, W. The relationship between anxiety, cal domains and TB is beginning, the present data high- depression and illness perception in tuberculosis paly suggests that healthcare programs must incorporate tients in Pakistan. Clinical Practice and Epidemiology mental health intervention. Despite the fact that tuber- in Mental Health 2008; 4(1), 4.

culosis is rarely considered in mental health programs ${ }^{9}$, 7. Adina, M.M, Necrelescu, O.L., Bondor, C., Trofor, mental health professionals should be integrated in TB A., Alexandrescu, D.\&Dantes, E. Depressive syndrome, control programs in order to minimize patient's suffer- anxiety and illness perception in Tuberculosis patients. ing and to reduce the impact of emotional distress on IN O. Braissant, H. Wakamatsu, I. Kuo-Kang, K. Altreatment. 
searches in Modern Medicine (pp 243-248). Cambridge: WSEAS Press, 2011.

8. Moussas, G., Tselebis, A., Karkanias, A., Stamouli, D., Ilias, I., Bratis, D., \& Vassila-Demi, K. A comparative study of anxiety and depression in patients with bronchial asthma, chronic obstructive pulmonary disease and tuberculosis in a general hospital of chest diseases. Ann Gen Psychiatry 2008, 7(7), 1-4.

9. Peltzer, K., Naidoo, P., Matseke, G., Louw, J., Mchunu, G. \&Tutshana, B. Prevalence of psychological distress and associated factors in tuberculosis patients in public primary care clinics in South Africa. BMC Psychiatry 2012; 1471-244X/12/89.

10. Deribew, A., Tesfaye, M., Hailmichael, Y., Apers, L., Abebe, G., Duchateau, L., \&Colebunders, R. Common mental disorders in TB/HIV co-infected patients in Ethiopia. BMC Infectious Diseases 2010; 10(1), 201.

11. Rubeen, R., Zareen, N., Zameer, S., Rasool, A. G., Naqvi, S. S. N., \&Iqbal, J. Anxiety and Depression in Tuberculosis Can Create Impact on Quality of Life of Patient. Acta MedicaInternational 2014; 1(2), 93.

12. Araújo GSd, Pereira SM, Santos DNd, Marinho JM, Rodrigues LC, et al. Common Mental Disorders Associated with Tuberculosis: A Matched Case-Control Study. PLOS ONE 2014; 9(6): e99551. doi:10.1371/ journal.pone.0099551.

13. Pais-Ribeiro, J., Silva, I., Ferreira, T., Martins, A., Meneses, R., \& Baltar, M. Validation study of a Portuguese version of the Hospital Anxiety and Depression Scale. Psychology, Health \& Medicine 2007, 12(2), 225237.

14. Smith, A. B., Selby, P. J., Velikova, G., Stark, D., Wright, E. P., Gould, A., \& Cull, A. Factor analysis of the Hospital Anxiety and Depression Scale from a large cancer population. Psychology and Psychotherapy: Theory, Research and Practice 2002, 75(2), 165-176.

15. Bjelland, I., Dahl, A. A., Haug, T. T., \& Neckelmann, D. The validity of the Hospital Anxiety and Depression Scale: an updated literature review. Journal of Psychosomatic Research 2002, 52(2), 69-77

16. Ibbotson, T., Maguire, P., Selby, P., Priestman, T., \& Wallace, L. Screening for anxiety and depression in cancer patients: the effects of disease and treatment. European Journal of Cancer 1994, 30(1), 37-40.

17. van den Heuvel, L., Chishinga, N., Kinyanda, E., Weiss, H., Patel, V., Ayles, H., ... \&Seedat, S. Frequency and correlates of anxiety and mood disorders among TB-and HIV-infected Zambians. AIDS Care 2013; 25(12), 1527-1535.

18. Ige, O. M., \&Lasebikan, V. O. Prevalence of depression in tuberculosis patients in comparison with non-tuberculosis family contacts visiting the DOTS clinic in a Nigerian tertiary care hospital and its correlation with disease pattern. Mental Health in Family Medicine 2011; 8(4), 235.

19. Aamir, S. Co-morbid anxiety and depression among pulmonary tuberculosis patients. Journal of the College of Physicians and Surgeons--Pakistan 2010; 20(10), 703-704.

20. Shen, T. C., Wang, C. Y., Lin, C. L., Liao, W. C., Chen, C. H., Tu, C. Y., \& Chung, C. J. (2014). People with tuberculosis are associated with a subsequent risk of depression. European Journal of Internal Medicine 2014; doi:10.1016/j.ejim.2014.10.006.

21. Volchegorskiŭ, I. A., Novoselov, P. N., \&Astakhova, T. V. [Impaired emotional sphere in patients with infiltrative pulmonary tuberculosis]. Problemy'TuberkulezaiBolezneiLegkikh2006; (11), 3-6.

22. Cohen, S., \& Herbert, T. B. Health psychology: Psychological factors and physical disease from the perspective of human psychoneuroimmunology. Annual Review of Psychology 1996; 47(1), 113-142.

23. Gerrish, K.,Naisby, A., \& Ismail, M. Experiences of the diagnosis and management of tuberculosis: a focused ethnography of Somali patients and healthcare professionals in the UK. Journal of Advanced Nursing 2013; 69(10), 2285-2294.

24. Moya, E. M., \& Lusk, M. W. Tuberculosis stigma and perceptions in the US-Mexico border. SaludPública de México 2013; 55(4), 498-507.

25. Saad, T., \&Tirkey, A. S. Tuberculosis Associated Stigma among Patients Attending Outpatient in Medical College Hospital in Sagar (Madhya Pradesh) in Central India. Research \& Reviews: Journal of Medical and Health Sciences 2013; 3(1), 126-131. 